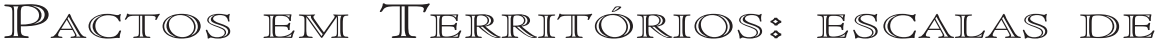

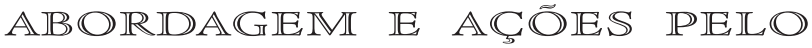 \\ $\mathbb{D} \mathbb{S} \mathbb{E} \mathbb{N} \mathbb{V} \mathbb{L} \mathbb{N} \mathbb{N} \mathbb{E} \mathbb{N} O$
}

\section{Carlos Brandão*}

RESUMIO

artigo expõe o ambiente dos debates contemporâneos sobre desenvolvimento, território e novos arranjos institucionais. Procura apontar alguns elementos teóricos e metodológicos para a formulação de pactos territoriais em contextos institucionais e históricos específicos como o brasileiro. Discute a necessidade de pactos que assumam o território como construção dinâmica e contingente e nexo de embates de forças e interesses divergentes, que devem ser articulados e contratualizados em estratégios de desenvolvimento.

ABSTRACT

he paper addresses to the contemporary debate on development, territory and new institutional frameworks. It highlights theoretical and methodological elements to support the building of territorial pacts, within the specific Brazilian historical and institutional context. It discusses the need of pacts which regards the territory as a dynamic construction, as an arena where different interests measure up to one another. In this way, it advocates for territorial pacts that must be linked to and negotiated within development strategies.

* Prof. Instituto de Economia da UNICAMP. 
O que faz falta é a proposição de um pacto territorial estrutural, conjunto de propostas visando a um uso do território coerente com um projeto de país e parte essencial desse projeto...[Porém]...O território continua a ser usado como palco de ações isoladas e no interesse conflitante de atores isolados" (SANTOS, 1987).

xiste hoje certo consenso, sobretudo nos meios intelectuais e políticos não-conservadores, de que ações coletivas pelo desenvolvimento, ao assumirem integralmente a natureza e a dinâmica do processo de transformações multidimensionais, devem ser promovidas, simultaneamente, em variados contextos (tecnológico, produtivo, social etc), coordenando diferentes níveis de governo (local, micro e meso regional, nacional etc), e tendo por base múltiplas institucionalidades.

Da mesma forma, há certo consenso no papel possível e desejável que deve ser desempenhado pelo território nesse contexto. Tratado devidamente como arena e campo catalisador, este pode assumir toda a conflitualidade inexorável e necessária à adequada pactação social pelo desenvolvimento. Assim, o território deve ser tomado como palco de conflitos, pressupondo a necessária construção permanente de canais institucionais, legitimação de interlocutores e de um espaço público de reflexão, mediação, barganha, incentivo ao diálogo e à constituição coletiva de diagnósticos de problemas e meios de seu enfrentamento compartilhado.

Importantes lições vêm das experiências de barganhas coletivas e das "soluções de compromisso" em torno de exigências conflituosas e contraditórias. Tais experimentos apresentam processos de aprendizagem institucional compartilhada e podem desaguar na construção de uma cultura da negociação. A concertação e a elaboração de ações convergentes ou não assumem a contingência e a variedade de trajetórias viáveis e respostas possíveis frente a problemas conjunturais e estruturais. "As concertações procuram fixar certas regras e seus limites. Em grande medida os novos pactos se distinguem em função de vários mix entre coordenação centralizada e descentralização desregulada, entre flexibilidade descoordenada e flexibilidade seletiva etc" (TAPIA, 2005, p.9).

Este ensaio procura apontar alguns elementos teóricos e metodológicos para a formulação de pactos territoriais em contextos institucionais e históricos específicos como o brasileiro. Analisa os limites e possibilidades de se abandonar atitudes acomodatícias, institucionalizar o envolvimento e promover o diálogo e a concertação contratualizada de interesses, buscando criar elementos políticos redutores de incertezas e neutralizadores de fatores de instabilidade, oportunismos e ciclos políticos, além de engendrar novos instrumentos de geração de escoIhas públicas e coletivas.

A partir dos anos 1980, observa-se com maior nitidez o surgimento de estruturas descentralizadas em vários países. Esse processo tem tomado configurações diferentes, a depender do contexto político e institucional de cada país. Além do movimento de descentralização e de co-responsabilidade e cessão parcial do poder decisório às instâncias subnacionais de governo, observamos o crescimento de arranjos horizontais, ou seja, articulados dentro de uma mesma instância de intervenção.

A questão que se coloca é: de que forma vão se estabelecer essas relações entre os diferentes níveis de governo? Dentre várias possibilidades de operacionalizar esses arranjos, a literatura recente tem citado a contratualização de estratégias de desenvolvimento como exemplo bem sucedido de relacionamento entre as diversas esferas de governo, viabilizando a formação de arranjos estáveis e eficientes. Assim, considerando a contratualização um modelo virtuoso, novas perguntas surgem: Quais são as vantagens dessa formalização contratualizada para as articulações verticais e horizontais? Arranjos informais não poderiam alcançar resultados virtuosos?.

Diferentes arranjos institucionais emergem em vários países, como os contratos regionais, metropolitanos e locais na França (Contrat de pays) e Itália (contratti d'area e patti territoriali), os acordos regionais e locais na Suécia (Regional/Local Growth Agreements) e as agências de desenvolvimento na Áustria, dentre outros. 
A experiência francesa é exemplar na descentralização de competências e na ampla articulação entre suas instâncias e níveis administrativos. A reforma do sistema de planejamento nacional delegou às regiões as atribuições de elaboração e gestão de um plano nacional de desenvolvimento, ao mesmo tempo em que autorizou o Estado a realizar contratos com as diversas esferas territoriais - região, departamento ou comuna -, embora, na prática, tais acordos formalizados tenham se limitado à esfera da região. A partir de então, o estabelecimento de regras claramente definidas entre o Estado e as regiões passou a ser oficializado por meio dos chamados "Contratos de Plano Estado-Região". Os contratos de plano foram reforçados, recentemente, como instrumentos de política regional pela Lei de 1995, LOADDT (Loi pour l'Amenagement et le Développement du Territoire), conhecida como Lei Voynet. Essa lei introduziu o conceito de desenvolvimento sustentável e incrementa o papel do pays (sub-região) no desenvolvimento de programas estratégicos de desenvolvimento; e coloca, ainda, como principal objetivo da política regional "corrigir as desigualdades de condição de vida dos cidadãos ligadas à situação geográfica e às suas conseqüências demográficas".

Tais experiências procuram contornar as graves disfunções acarretadas pelas competências superpostas, procurando dar transparência ao conflito de interesses e buscando maior coesão e solidariedade no sentido do desenvolvimento durável.

O estudo dos casos internacionais pode aportar interessantes lições; porém, o Brasil não pode ou precisa copiar modelos de desenvolvimento. São os seguintes pontos importantes da agenda científica: discutir as técnicas de formulação e disseminação dos modelos analíticos e de intervenção; pesquisar as elaborações teóricas e seu significado discursivo, ideológico e político e; averiguar como são promovidos e divulgados, via importações, incorporações, empréstimos e re-significações, em uma espécie de difusão transnacional de experiências específicas que são convertidas em referenciais de validade universal, com aceitabilidade generalizada. Assim, o "'modelo' também pode significar um ideal normativo, um paradigma para ação, a referência a um exemplo ou imagem que serve de inspiração ou que se busca reproduzir nas instituições e práticas sociais" (LIMA JUNIOR, 2006, p.3).

Se o Brasil vive atualmente mais um - recorrente nos espaços subdesenvolvidos - ciclo de importação de modelos interpretativos, é conveniente ter cautela com suas marcantes especificidades, quando se vai realizar análises comparativas de experiências internacionais e sua pluralidade de arranjos institucionais possíveis.

Recentemente, o país passou por inovações em sua institucionalidade associativa municipal. Vários arranjos, como os consórcios intermunicipais e as articulações de municipalidades em torno de bacias hidrográficas, vêm conhecendo grande aprendizagem institucional. Esse tema tende a ganhar maior destaque no momento atual com a lei que criou a normatização de contratos para a institucionalização de consórcios públicos e de contratos de programa que incentivam a gestão associada de serviços públicos. Tais atuações conjuntas - buscando a solução de problemas "entrelaçados", que extrapolam limites territoriais, competências e âmbitos restritos de poder, a fim de realizar obras, serviços, atividades etc que são de interesse supralocal, congregando forças políticas, recursos financeiros e de gestão, os quais superam a dispersão dos esforços - podem se constituir em importante ação capaz de ampliar a interlocução inter-institucional e inter-escalar.

Mas nem tudo é êxito nesses experimentos. Spink (2006a) coloca a seguinte importante questão:

Será que a Constituição de 1988, que transferiu responsabilidades consideráveis aos estados e, especificamente, aos municípios, contribuiu efetivamente para o desenvolvimento de um processo de formulação de políticas públicas de base territorial ou ao contrário, e por causa das inúmeras condicionalidades e obrigações impostas pela União sobre os gastos municipais, produziu o equiva- 
lente a um modelo de franchise onde o papel principal que restava para cada município era a implementação de políticas, programas e ações desenhadas e formuladas no governo federal? (SPINK, 2006a)

Novas categorias territoriais potencializam o surgimento de processos associativos locais, permitindo a viabilização de projetos nas mais diversas áreas. Como muitos desses lugares não apresentam porte ou densidade para a provisão de serviços públicos, o consorciamento possibilita ganhos de escala, representando alternativa importante para o enfrentamento de variados problemas, tais como disposição de lixo e abastecimento de água. Na maioria das vezes, tais formas cooperativadas em associações intermunicipais impuseram-se pela necessidade e por problemas concretos.

Nos casos em que a legislação não prevê estruturas específicas para lidar com problemas comuns entre cidades, os consórcios ou associações de autoridades locais são geralmente utilizados. Sob esse sistema, as municipalidades participantes se agregam voluntária e, geralmente, temporariamente. Os municípios delegam certos poderes para a autoridade comum que, então, exerce esses poderes em seu próprio nome.

Considerando apenas os arranjos horizontais no Brasil, observamos que estes ganham relevância ainda maior se considerarmos as transformações recentes, como o fortalecimento dos municípios enquanto entes federados, após a Constituição de 1988. Com a proliferação do número de municípios - muitos dos quais apresentando grande fragilidade administrativa, com quadros técnicos insuficientes e/ou pouco qualificados e, sobretudo, situação financeira bastante debilitada -, a associação intermunicipal se apresenta enquanto alternativa para a superação de dificuldades de várias naturezas relacionadas à oferta de bens e serviços coletivos. Há, também, outras formas de parcerias intermunicipais, como as associações, as agências, os fóruns, as empresas, as autarquias, as redes e as câmaras intermunicipais, as quais têm auxiliado os municípios na solução de problemas comuns que transcendem os limites de uma única localidade.

Entretanto, apesar desses avanços, o pacto federativo brasileiro está esgarçado, carente de mecanismos de coordenação federativa e marcado antes por ações competitivas do que cooperativas. Sua manifestação mais evidente foi o acirramento da guerra fiscal na década de 1990, que explicitou uma disputa ferrenha, uma verdadeira "guerra" dos lugares, pela implantação de novos investimentos entre estados e municípios, inclusive entre municípios de uma mesma região metropolitana.

A correlação de forças políticas presentes no Brasil tem dificultado o avanço da redefinição de responsabilidades e competências. A forma de operação do federalismo brasileiro pouco estimula a cooperação, além de haver "uma distribuição irregular de competências e capacidades" (ALMEIDA, 2005, p.38), bem como muitas indefinições quanto à transferência, subordinação, complementaridade de atribuições e mecanismos compartilhados. A autora afirma que:

do ponto de vista das relações intergovernamentais, a federação brasileira é um arranjo complexo em que convivem tendências centralizadoras e descentralizadoras, impulsionadas por diferentes forças, com motivações diversas, produzindo resultados variados [...] Assim, tendências descentralizadoras e impulsos centralizadores materializaram-se em instituições que fizeram da federação um arranjo cooperativo complexo, no qual governo federal, estados e municípios articularam-se de maneiras diversas nas diferentes áreas de ação governamental (ALMEIDA, 2005, p.38).

Não cabe aqui fazer uma discussão sobre federalismo cooperativo versus federalismo não cooperativo; no entanto devemos chamar a atenção para duas questões. Em primeiro lugar, é mais coerente pensar que atitudes não-cooperativas são próprias de agentes federativos. Assim, por ser intrinsecamente tensa e conflitiva, torna-se necessário o estabelecimento de regras e de um elemento regulador que organize os processos de divergências mais agudas no seio da federação, de forma a impedir perdas mais graves para a sociedade como um 
todo, frente ao municipalismo autárquico brasileiro. Nessa perspectiva, o problema central não estaria no caráter conflituoso da nossa federação e, sim, na forma de balizamento dos diversos interesses, que carecem de um ordenamento mais orgânico e sistêmico. Faltam molduras institucionais capazes de concertar interesses díspares.

Em segundo lugar, formas mais cooperativas de relacionamento entre entes federativos, também, implicam em alguns problemas, pois além da dificuldade em se estabelecer responsabilidades mais claras, a cooperação pode resultar em resultados negativos, como a subordinação dos entes mais fracos aos mais fortes, já que cooperação implica em (re)definição de poder. O desafio é, portanto, possibilitar a cooperação sem que esse processo leve a relações assimétricas e à imposição de interesses de uns sobre os outros. Este é um caso típico quando se envolve negociação no âmbito metropolitano.

Como as experiências associativas existentes mostram, estas, geralmente, funcionam em torno de uma cidade pólo (no caso metropolitano, na cidade sede da região) ou um prefeito coordenador, uma liderança forte, criando um desequilíbrio entre as partes e atribuições diferenciadas de responsabilidade. Quanto mais homogêneos em relação ao tamanho, ao poder político e aos recursos materiais, maiores as chances de cooperação. Ao contrário, relações assimétricas desestimulam a cooperação: os mais fracos podem duvidar que seus interesses sejam atendidos, enquanto os mais fortes dispensem esse tipo de articulação.

Diante desse quadro, portanto, quais seriam as alternativas para estimular as associações horizontais? O Brasil já tem uma boa experiência em cooperação intermunicipal e, provavelmente, muito de seu desenvolvimento depende de aperfeiçoamento dos instrumentos já existentes. No entanto, com base nas discussões feitas acima e dos exemplos colocados, podemos indicar alguns pontos no sentido de estimular associações horizontais e, assim, avançar na problemática da coordenação legitimada e estratégica. Busca-se, dessa forma, traduzir anseios e aspirações coletivas, bem como construir a inter-governamentalidade ou interinstitucionalidade adequada a cada problema concreto com base na associação voluntária.

Múltiplas configurações institucionais estão disponíveis para serem construídas concretamente em territórios e problemáticas específicas. Cada um dos formatos organizacionais apresenta potencialidades e, também, limites. Cabe identificá-los e discutir democraticamente sua forma de implantação. Uma composição de várias configurações também pode ser a estratégia mais adequada. Spink (2006b) realiza uma interessante comparação entre os arranjos metropolitanos e os consórcios inter-municipais:

\begin{abstract}
Em termos analíticos e pragmáticos, institucionalmente as regiões metropolitanas ainda não conseguiram se legitimar. Em comparação, os consórcios intermunicipais começam com objetivos exclusivamente organizacionais, complementares à institucionalidade municipal. Se alguns destes adquirem uma institucionalidade maior será porque ganharam o respeito e a valorização a partir de suas ações e não por causa de sua presença formal. [...] Além das explicações mencionadas podemos também considerar questões como a gestão da complexidade interorganizacional - os consórcios se iniciam mono-tematicamente enquanto as regiões metropolitanas normalmente começam com uma agenda grande de questões - e sua relação com a formulação de política pública em situações multipolares. Posto de maneira simples, os consórcios têm como vantagem o fato de começar pequeno tanto em termos de número como em foco e voluntariedade; nestas condições, a construção de uma cultura de ação é mais fácil (Spink, 2006b, p.8).
\end{abstract}

A contratualização intermunicipal e metropolitana pode ser uma saída para diminuir os riscos políticos dos acordos, tornando-os mais estáveis. Essa pactação pode ser incentivada pelo governo federal por meio de mecanismos de incentivo à criação de associações municipais. Pode-se priorizar o repasse de verbas a projetos dos municípios com ações compartilhadas, desde que esses se enquadrem nos objetivos gerais da Política Nacional de Desenvolvimento e que essa liberação 
de recursos seja condicionada à apresentação de resultados e de contrapartidas (co-responsabilização).

Se a formalização, levada a seu extremo pela contratualização, é uma saída para diminuir os riscos políticos e partidários do sistema brasileiro, parece paradoxal que indiquemos, também, a formação de arranjos informais, os quais, embora possam ser extremamente frágeis, podem congregar interesses legítimos e permitir o diálogo para o surgimento de propostas políticas e, até mesmo, evoluir para estruturas mais formais de cooperação.

Deve-se ressaltar, também, que a formação dessas associações deve acontecer de forma voluntária e não compulsória, de maneira a permitir que os interesses legítimos sejam perseguidos. Algumas autoridades e autores têm sugerido, como uma saída para a construção de arranjos mais harmoniosos, a discussão, inicialmente, de arranjos informais, realizados para projetos específicos, e, posteriormente, a elaboração de uma estrutura institucional. Esta seria uma alternativa importante, também, para a criação de uma institucionalização metropolitana, já que a tensão entre os interesses dos municípios sede e periféricos está quase sempre presente.

Como já observamos, uma condição para a realização de associações é a existência de relações mais igualitárias e homogêneas entre os membros. Sabese que, do ponto de vista estrutural, essa condição é difícil de ser alcançada. Além disso, existe a discussão sobre o papel de uma liderança, seja municipal, seja regional, nesses processos.

Como consolidar interlocutores legítimos, uma validação social cidadã e promover o monitoramento e a reavaliação constante das políticas implementadas são grandes desafios. Propõe-se construir, pedagogicamente, um espaço de contatos e diálogos freqüentes para a busca da confluência de ações e propósitos, criando forças-tarefa de animação e envolvimento e múltiplas arenas de concertação de interesses, tais como consórcios, fóruns regionais de desenvolvimento, comitês etc.

É fundamental construir táticas e estratégias que envolvam um processo delicado de aprendizado conflituoso, o qual irá requerer o resgate da lógica do projeto e das ações planejadas, participativas e politizadas. Nesse contexto, as ações políticas devem ser mais ágeis, potentes, sistemáticas e empreendidas, simultaneamente, em várias direções escalares. Deve-se pretender, com tais políticas, a "recomposição territorial" por meio da ação planejada; a reconstrução de espaços públicos e dos canais institucionalizados de participação, destruídos pelas políticas neoliberais e; a criação de variadas arenas que possam aglutinar e dar vazão às diferentes reivindicações e interesses.

O poder público deve cumprir papel-chave nesse processo. Deve estar bem capacitado, com recursos materiais e humanos para incentivar a discussão democrática, garantindo transparência, acompanhamento, fiscalização e o monitoramento permanentes, além do papel decisivo de impor e fazer cumprir sanções e benefícios.

Romper com as forças desarticuladoras e os pactos de dominação interna, bem como estabelecer estímulos à identidade/diversidade/diferenciação/variedade, são tarefas longas e difíceis, que devem, no percurso, ser, estruturalmente, participativas e pedagógicas.

É necessária ampla repactuação de forças antagônicas, bem como contratualização dos compromissos. A inspiração para tal orientação politizada vem das políticas de concertação da União Européia. Em outras palavras, a articulação de um novo pacto, em que as ações tenham horizontes de longo prazo, tendo por base contratos-programas, criteriosamente definidos e territorializados.

Contudo, os estudos internacionais têm demonstrado os constrangimentos a que estão submetidas as ações públicas que buscam fomentar o diálogo social em ambientes de baixa legitimidade e falta de confiança dos agentes sociais.

O Brasil vive crise social e política de natureza estrutural. Recrudesceram velhos impasses e recorrências históricas de nossa reprodução social, transformando o padrão de sociabilidade anteriormente erguido, corroendo as bases da esfera pública e desarticulando possíveis ações construtivas da Nação. 
Nesse contexto, a tarefa de construção de novo contrato social é difícil, porém urgente e necessária. O País passou por rápidos e profundos processos de ruptura dos laços de solidariedade, alargou os espaços do privatismo e da clientela institucionalizada, ampliando suas carências de compromissos sociais e valores universais. A lógica do proveito próprio, com baixíssima capacidade de suporte e normas de convívio, acaba por consolidar o imediatismo do presente, sem valores do passado e "perspectivas" de futuro. Os espaços público e privado perderam vários elementos de distinção.

A incorporação de alguns estratos sociais se deu sem a integração das massas aos circuitos de produtividade modernos, sem o desenvolvimento dos direitos individuais e com cidadania inconclusa, formando, assim, uma camada de deserdados e desclassificados. Assistimos a toda sorte de precarização, informalização, exclusão e marginalização, com o agravante de que agora conta-se com o fim da legitimidade da proteção social, enquanto várias facções de classe ingressam nas esferas subterrâneas da economia ou mesmo na acumulação ilícita. Uma imensa "massa sobrante" e "inativa", grande parte depositada nas grandes metrópoles, acaba encontrando "refúgio" nas instâncias marginais da sociedade, jazendo ao largo dos preceitos legais e das garantias sociais, formando enorme massa de não-cidadãos, destituídos de dignidade, segurança, proteção e status; submetidos ao infraconsumo, mesmo das necessidades mais básicas.

Por outro lado, uma minoria que goza de direitos civis plenos, foi submetida, como nos ensina Celso Furtado, à imposição e difusão de padrões de "vida moderna" e de aspirações de consumo estandardizado. Tal grupo encontrou uma economia urbana em expansão e uma fronteira agrícola fluida, em que seus diversificados interesses puderam ser contemplados.

Na ausência de expectativas de auto-crescimento, a fração majoritária da sociedade está mergulhada em inquietude e insatisfação difusas, não aglutinadora e não geradora de uma mínima convergência de finalidades, capaz de cimentar a convivência social civilizada e a reprodução econômica ampliada. A violência aberta e a sociabilidade estreita são apenas dois sintomas desta situação de ausência de um projeto nacional de desenvolvimento.

Por outro lado, minam-se os fundamentos da complexa articulação entre o "poder nacional" e os poderes locais, talvez negando, hoje, definitivamente, o pacto federativo que costurasse interesses dispersivos de uma "civilização" cicatrizada pelo peso da história de profundas heterogeneidades estruturais (social, regional e produtiva) e pelo movimento secular do pêndulo da centralização/ descentralização política e da (re)distribuição de competências entre as esferas de governo.

O ambiente é complexo, pois as malhas de solidariedade e as redes de amortecimento baseadas naquela mobilidade estrutural (intergeracional e geográfica) que amparavam os de baixo se definharam. Deixamos as estratégias de sobrevivência minimamente coletivas para ingressarmos nas táticas de sobrevivência da vida privada. O mais grave é que grande parte da pobreza e da miséria se encontra em grandes centros urbanos, que não conseguem prover serviços públicos, bens coletivos, empregos etc de qualidade.

A importante questão é se perguntar o que pode significar a persistência secular de uma sociedade cindida entre uma grande maioria que se localiza subordinadamente na sociedade, configurando uma verdadeira massa de nãocidadãos, e uma pequena minoria privilegiada que goza de direitos civis e garantias sociais plenos?

É preciso ampliar as arenas publicizadas e os canais institucionalizados de participação promovendo o diálogo coletivo. O espaço público não pode, no Brasil, ser apenas aquele mero sinalizador e facilitador do espaço privado, servindo tãosomente à promoção de ambiente salutar para micro-iniciativas. Deve, sim, costurar, em várias lógicas e escalas, macro-decisões estratégicas que articulem e dêem coerência ao processo duradouro de desenvolvimento, enquanto alargamento do horizonte de possibilidades, reelaborando, continuamente, arenas de coordena- 
ção de interesses, diálogos, conflitos e consensos em ambiente de heterogeneidades e assimetrias.

Se um problema se manifesta em uma escala - por exemplo, o desemprego municipal -, suas determinações podem estar em outra esfera (na política macroeconômica na escala nacional). Muitas vezes, a legitimidade e a eficácia das ações podem fundar-se em outra escala, para além do foco destas. É o que acontece, por exemplo, na escala metropolitana. As estratégias de atuação conjunta, fundamentais no enfrentamento de problemas comuns que extravasam os limites jurídico-administrativos, vocalizando com maior potência reivindicações supralocais, podem ter grande êxito, apesar dos limites da participação. Como afirma Teixeira (2006, p.10):

talvez, a frágil presença das organizações sociais e dos legislativos locais (...) esteja muito mais associada com a cultura política de se organizar socialmente e reivindicar políticas públicas no âmbito municipal e estadual, não havendo, portanto, uma presença significativa de movimentos reivindicatórios de perfil metropolitano, o que poderia contribuir para a construção de espaços públicos metropolitanos, potencializando, dessa maneira, a contribuição da sociedade civil para a gestão da RM.

Para aperfeiçoar essas ações que extrapolam a escala local é preciso pactuar, com definição e registro em contratos claros, a contribuição financeira e o acesso a possíveis fundos, explicitando a contribuição das partes em termos de capacidade gerencial, participação da comunidade, compartilhamento de equipamentos, equipes etc.

Embora sejam possíveis as articulações nos níveis intermediários, a motivação para a realização dessas associações locais se torna mais evidente, na medida em que a solução de vários problemas municipais extrapola as suas fronteiras jurídico-administrativas. As concertações regionais e metropolitanas se tornam poderosas, cujos exemplos mais evidentes são os serviços de água, esgotamento sanitário, depósito de lixo, saúde e transportes. Além disso, mesmo quando seja possível a resolução dos problemas de forma isolada, a ação conjunta pode implicar em menores gastos e, portanto, ser extremamente benéfica, como, por exemplo, na realização de compras em conjunto para alcançar descontos mais significativos. Outro aspecto positivo dessas associações é a possibilidade de viabilizar projetos considerados inviáveis de serem realizados individualmente, como, por exemplo, a compra de um equipamento muito caro, a formulação de projetos, o compartilhamento de máquinas e equipamentos, centros de tecnologia ou de design, a destinação final dos resíduos sólidos numa perspectiva metropolitana etc.

É indispensável, nestas ações consorciadas, a assunção, amplamente pactuada, de responsabilidades, custos e benefícios, objetivando a tão difícil e desafiadora compatibilização entre eficiência e eqüidade. Há, por exemplo, marcados conflitos imanentes à difícil definição da parcela que cabe aos municípios "mais ricos" e aos "mais pobres" da região. Daí a necessidade de assegurar espaços amplos de discussão, os quais realizem o mais justo balanceamento entre, por um lado, ônus ou sobrecarga, devidos às incumbências requeridas e, por outro, benefícios e vantagens das políticas concertadas. Um exemplo clássico é a discussão e os conflitos em torno da localização de aterros sanitários regionais nessas negociações.

A ação supralocal geralmente pode lograr grande êxito em aumentar o "poder de diálogo, pressão e negociação" vis-à-vis ações isoladas dos municípios de determinada região, contribuindo para aumentar a acessibilidade a outras escalas espaciais e a outros níveis de governo superiores. Não obstante, é necessário nessas experiências conjuntas, que haja solidariedade institucional para evitar os conflitos de competência e as sobreposições entre as distintas esferas de poder.

A definição da escala supralocal é complexa e necessária. Mesmo quando o recorte é natural, como o dos consórcios intermunicipais de bacias hidrográficas, há complexidade na definição da política. A escala da bacia é a justa e devida escala para os problemas de gestão dos recursos hídricos e do saneamento 
ambiental, mas não para outros problemas, como tem sido freqüentemente pensado no Brasil, talvez dada à extrema carência de outras ações regionais que não a dos comitês de bacias.

Recentemente (BRASIL, 2005) se elaborou uma proposta governamental de "pactos para a gestão territorial integrada", no âmbito do Ministério do Planejamento, com o desafio de incitar o processo de concertamento e pactuação que "pressupõe a integração da lógica territorial à visão setorial consolidada na administração pública brasileira". Tal proposta sugere a criação de instrumento de formalização "que organize as ações compromissadas pelos atores pactuantes", e que "na ausência de instrumentos jurídicos adequados, prevalecerá o comprometimento público dos representantes das instituições" (BRASIL, 2005, p.21). Levanta-se a perspectiva de variados instrumentos de gestão orientados para a conciliação de interesses, em diversos níveis de governo e escalas espaciais.

Se cada problema tem a sua escala espacial específica, é preciso enfrentá-lo a partir da articulação dos níveis de governo e das esferas de poder pertinentes àquela problemática específica.

Nesse sentido, a experiência européia de implementação dos Contratos de Plano Estado-Região é bastante pedagógica das virtudes das políticas públicas que diagnosticam e tratam de forma adequada as escalas espaciais e bem definem os instrumentos a serem utilizados no enfrentamento dos problemas identificados.

Vão sendo construídos, assim, politicamente, reforços nas relações de horizontalidade (na mesma escala) e de verticalidade (nas escalas abaixo e acima daquela em que se implementa a política). Explicitam-se as relações de oposição/ contradição/complementaridade presentes em determinado território, podendo assegurar novo patamar de convívio de escalas, níveis e esferas, lançando mão de variados instrumentos, politizando as relações, construindo cidadania e buscando combater as coalizões conservadoras que procuram preservar seus privilégios naquela escala restrita sob seu domínio.

O processo de Desenvolvimento envolve e exige transformação estrutural em vários aspectos (produtivo, social, regional etc) e resulta de variadas e complexas interações sociais tecno-produtivas, todas voltadas ao aumento de autodeterminação da sociedade. Deve promover a ativação de recursos materiais e simbólicos e a mobilização de sujeitos sociais e políticos, buscando ampliar o campo de ação e aumentando a liberdade de decisão. Exige, necessariamente, envolvimento e legitimação de ações disruptivas; portanto, envolve tensão, eleição de alternativas, segundo horizontes temporais de curto, médio e longo prazos. As políticas de desenvolvimento devem agir sobre a totalidade do tecido sócio-produtivo; pensar o conjunto territorial como um todo sistêmico, promovendo ações concertadas naquele território. Ou seja, por um lado, explorar de forma mais criativa possível suas externalidades positivas e vantagens, não apenas de âmbito estritamente local, mas, também, políticas de desenvolvimento em escala (micro, meso e macro) regional, constituindo mesas de comprometimento e identificação das forças contrárias ao avanço da construção da eficiência e da eqüidade.

Nesse contexto, no debate aqui levantado, é fundamental definir os territórios como resultantes da operação dos processos de especialização e diferenciação materiais da sociedade. É necessário robustecer as endogenias simultâneas das escalas nacional, regional e local, e construir, permanentemente, integração e coesão produtiva, social, política, cultural, econômica e territorial; promover mudanças no acesso a ativos e propriedades, buscando habilitar os atores mais destituídos e marginalizados de determinado território; ativar recursos materiais e simbólicos, bem como mobilizar sujeitos sociais e políticos, buscando ampliar o campo de ação da coletividade e aumentar sua autodeterminação e liberdade de decisão; buscar novos arranjos institucionais que possibilitem a articulação de pactos e contratos sociais territorializados; tomar o território enquanto potência vigorosa de transformação, porém discutindo onde estão os centros de decisão e seus mecanismos de legitimação; analisar a ação de sujeitos sociopolíticos, po- 
rém não apenas enquanto suporte de dada estrutura; lembrar que as estruturas e os sujeitos são processos histórica e geograficamente determinados e mediados; analisar hegemonias, poderes e hierarquias, construindo e hierarquizando mediações diversas (espaciais, sociais, políticas, monetárias, financeiras, macroeconômicas, microeconômicas, inter-estatais, geoeconômicas e geopolíticas), ter presente a dinâmica de ação das facções das classes sociais e analisar os sujeitos portadores de decisões transformadoras e; assumir a conflitualidade inerente, a contenda de interesses múltiplos e os variados loci de possibilidades de concertação, ou não, de projetos em disputa.

Em suma, a agenda do desenvolvimento envolve abordar devidamente: a interurbanidade; a intersetorialidade produtiva e a inter-regionalidade territorial. Ter presente nas análises ações nos meio rural e urbano, não apenas enquanto contexto, mas como espaço construído conflituosamente. Discutir relações interurbanas e intra-urbanas, mas também, no âmbito produtivo, as relações microdinâmicas. Analisar os encadeamentos para trás e para frente ao longo dos elos das malhas produtivas, os nexos de complementaridade, as inter e intravinculações setoriais.

Todas essas análises e possibilidades de construção de pactos e contratos territorializados devem conceber o território não como mera variável de análise, um dado da realidade ou um sítio fixado, mas como uma construção social, por natureza conflituosa; uma produção coletiva, dinâmica, multidimensional, com trajetória histórica em aberto. O território é unidade privilegiada de reprodução social, denominador comum, desembocadura, encarnação de processos diversos e manifestação de conflitualidades.

É por isso que não se pode ter uma visão uni-escalar. A abordagem multiescalar provê enfoques de observação passíveis de revelar as articulações e mediações entre os cortes local, regional, nacional etc. Nesse sentido, selecionar a escala mais conveniente dos problemas faculta melhor diagnosticá-los e possibilita sugerir coalizões de poder e decisões estratégicas sobre como enfrentá-los.

O território torna-se também espaço da indeterminação, da contingência, lócus de lutas políticas, das "possibilidades", como espaço da indeterminação e da contingência, lócus de lutas políticas.

O território que deveria ser visto como ambiente politizado, em conflito e em construção, é visto muitas vezes por acadêmicos e políticas de desenvolvimento como ente mercadejado e passivo, mero receptáculo. O que é fruto de relações sociais aparece como relação entre objetos. Há uma coisificação; o território parece ter poder de decisão, é transformado em sujeito coletivo, assumindo uma perspectiva que ressalta apenas a concórdia de projetos e a conciliação de interesses que se apresentam orquestrados em determinado território. Dissolvem-se ou ocultam-se as contradições, formando um conjunto compósito, uma regência ou compromisso territorial que tudo parece ajustar e harmonizar.

Porém, território envolve, necessariamente, arbítrio, criação, nexo, poder. Não se pode negligenciar a incerteza pelas trajetórias em aberto, as quais são construídas pelas coalizões sociais em disputa e que não estão predeterminadas pelo consenso territorializado, mas dependem da correlação de forças políticas de cada conjuntura social e escala espacial específica. As escalas, também.

Devem ser trazidas para o terreno social, incerto e móvel, daquilo que está em disputa. Nem as estruturas e lógicas econômicas nem as heranças históricas em si determinam e instauram escalas (...) diferentes agentes propõem diferentes escalas e em diferentes escalas se dispõem (VAINER, 2006, p.17).

A realidade tem negado as elaborações teóricas abstratas "uniescalares". Em todo o mundo, as políticas de desenvolvimento, com maiores e melhores resultados, são justamente as que não discriminam nenhuma escala de per si (considerando que uma escala seja melhor que outra, devendo ser privilegiada na ação), mas, sim, reforçam as ações multi-escalares - microrregionais, mesorregionais, metropolitanas etc -, no sentido de (re)construir as escalas espaciais (analítica e politicamente) mais adequadas a cada problema concreto a ser diagnosticado e 
enfrentado. A partir dessa concepção moderna, deve-se procurar estabelecer os pactos territoriais. Se território for isso, uma unidade privilegiada de reprodução social, denominador comum, desembocadura, encarnação de processos diversos e manifestação de conflitualidades, então, as indagações analíticas deveriam passar por: Quais atores, agentes e sujeitos? Quais são seus interesses concretos, seus instrumentos táticos e estratégicos etc? Atuam em que escala espacial? As determinações dos fenômenos estudados se dão em que escala espacial? Em que escala esses fenômenos se manifestam (local, metropolitana, nacional etc)? Onde estão os Centros de Decisão e Comando determinantes dos "fatos territoriais" sob análise?

Territórios são construções (sociais, discursivas e materiais) e, também, matrizes (REIS, 2005). Formam a rede matricial interna dos territórios (sua capacidade dinâmica), tanto as "proximidades" (contexto, co-presença, conhecimentos e identidades partilhados de forma coletiva) quanto as "densidades" ("que exprimem-se em interações continuadas, em aprendizagens, competências e externalidades, em 'ordens constitucionais' que coordenam a ação de atores sociais" (pg.16).

Estudar o agir, o comportamento orientado, dotado de propósitos, intencionalidades, para atingir determinados fins é a principal tarefa dos estudos territoriais. Estratégias de desenvolvimento são ações disruptivas e inventivas, legitimadas coletivamente. É o caso apresentado por Ferreira e Costa (2006), os quais discutiram os êxitos do "Pacto do Cariri" e destacaram, entre outros, o papel das informações disponibilizadas, que é o de mobilizar não apenas uma fração da sociedade, mas lograr o monitoramento constante e participativo da coletividade.

Teorizar sobre ações com intencionalidade transformadora em determinado território requer uma agenda interpretativa extensa e complexa, como a de elaborar novos instrumentos analíticos que melhor entendam a interação social construtora de autonomia. Os desafios analíticos e de ação política de natureza territorial/escalar são enormes, pois as escalas hierárquicas em que as atividades humanas são estruturadas mudam constantemente. Não obstante, permanece a sensação que "as escalas são imutáveis ou mesmo totalmente naturais, em vez de produtos sistêmicos de mudanças tecnológicas, formas de organização dos seres humanos e das lutas políticas" (HARVEY, 2000, p.108).

Discutir estratégias territorializadas de desenvolvimento passa, do meu ponto de vista, por encontrar a escala adequada para a definição de determinado campo em que os problemas são mais bem visualizados e quais instrumentos e medidas e ações concretas públicas serão acionadas sob aquele prisma particular de observação. Nesse sentido, consideramos que é imprescindível buscar construir estratégias multiescalares e encontrar a escala adequada que defina determinado campo no qual a decisão deve ser tomada.

Os embates políticos e ideológicos mobilizam e acionam, instauram e rompem escalas, num processo em que narrativas escalares estruturam e fundamentam estratégias e táticas, configurando arenas e objetos em disputa. Não apenas as escalas se transfiguram, como seu próprio significado e nomeação indicam redefinições de sujeitos e relações (...) Localismos, nacionalismos, regionalismos, globalismos, todos esses modelos e projetos devem ser incessantemente interpelados. Afinal de contas, o poder, mais do que nunca (...) está na capacidade de articular escalas, de analisar e intervir de modo transescalar (VAINER, 2006, p.28).

É preciso construir mesas de diálogo e levantamento de problemas e discussão da capacidade coletiva de sua resolução, buscando a articulação com os níveis de governo e as esferas de poder pertinentes àquela problemática específica; explicitar os conflitos de interesse e construir coletivamente a contratualização das políticas públicas. Esses contratos devem articular, horizontalmente, os agentes políticos de determinada escala. Deve-se, ainda, submeter circuitos mercantis, sóciopolíticos à circunscrição pactual em dado território, bem como engendrar um ação coletiva que seja pedagógica, que densifique a consciência social cidadã e a legitimação política. 
Pensar as possibilidades de armar contratos sociais territorializados de desenvolvimento envolve entender o território como ligadura, junção, confluência, ao mesmo tempo em que este encerra conflitualidade, contenda de interesses múltiplos e lócus de possibilidades de concertação de projetos em disputa.

Se o processo de desenvolvimento envolve o fortalecimento de uma dialética previsibilidade/imprevisibilidade, é decisivo ter consciência de seu caráter contingente, incerto, de "história em aberto", à espera de forças que lhe dêem conteúdo.

\section{Referê̂ncials}

ALMEIDA, Maria Hermínia T. Recentralizando a federação? Revista de Sociologia e Política, Curitiba, n.24, p. 29-42, jun. 2005.

ARRETCHE, Marta. Apresentação dossiê federalismo. Revista de Sociologia e Política, Curitiba, n.24, p. 41-67, jun. 2005.

BRANDÃO, Carlos. Território e desenvolvimento. Campinas: Editora da Unicamp. ; ALVES, Maria Abadia. Território e pacto pelo desenvolvimento: o caso da escala metropolitana de análise e ação In: COLÓQUIO INTERNACIONAL SOBRE PODER LOCAL, 10., 2006, Salvador. Anais... Salvador: CIAGS/UFBA, 2006. 1 CD-ROM.

BRASIL. Pactos para a gestão territorial integrada. Brasília: Ministério do Planejamento.2005. (texto para discussão).

DINIZ, Clélio Campolina; CROCCO, Marco(Org.). Economia regional e urbana: contribuições teóricas recentes. Belo Horizonte: Editora da UFMG, 2005.

FERREIRA, Márcio R.; COSTA, Márcia. Gestão compartilhada e cidadania: um estudo da experiência do "Pacto do Novo Cariri". In: COLÓQUIO INTERNACIONAL SOBRE PODER LOCAL, 10., 2006, Salvador. Anais... Salvador: CIAGS/UFBA, 2006. 1 CD-ROM.

FISCHER, Tânia (org.). Gestão do desenvolvimento e poderes locais: marcos teóricos e avaliação. Salvador: Casa da Qualidade, 2002. 341p.

GONCALVES, Maria Flora; BRANDÃO, Carlos A.; GALVÃO, Antônio C.. Regiões e cidades, cidades nas regiões: o desafio urbano-regional. São Paulo: Editora da Unesp, 2003.

HARVEY, David. Espaços da esperança. São Paulo: Loyola. 2000

. A produção capitalista do espaço. São Paulo: Anna Blume, 2005.

A brief history of neoliberalism. Oxford: Oxford University Press, 2005.

KEINERT, Tânia et al. Inovação e cooperação intergovernamental. São Paulo: Annablume, 2006.

LIMA Jr., Pedro Novais. Apontamentos sobre o trabalho teórico para afirmar Barcelona como um modelo de planejamento urbano. In: COLÓQUIO INTERNACIONAL SOBRE PODER LOCAL, 10., 2006, Salvador. Anais... Salvador: CIAGS/UFBA, 2006. 1 CD-ROM.

REIS, José. Uma epistemologia do território. Coimbra: Faculdade de Economia da Universidade de Coimbra, Centro de Estudos Sociais, 2005. Disponível em: <http://www.ces.uc.pt/jr/publics.htm>.

RIBEIRO, Ana Clara Torres et al. Por uma cartografia da ação: pequeno ensaio de método. Cadernos IPPUR, Rio de Janeiro, ano XVI, n.1, p.33-52, jan. / jul. 2002.

ROESCH, Sylvia; FISCHER, Tânia; MELO, Vanessa P.(Org.). Gestão social para o desenvolvimento: casos para ensino. Salvador: CIAGS. 2004. 
SANTOS, Milton. O espaço do cidadão. São Paulo, Hucitec, 1987.

SANTOS, Boaventura Souza. Renovar a teoria crítica e reinventar a emancipação social. São Paulo: Boitempo, 2007.

SMITH, Neil. The end game of globalization. New York: Routledge, 2005.

SPINK, Peter. Descentralização e o pacto federativo do ponto de vista dos poderes locais: política federal e ação local no programa gestão publica e cidadania os casos de educação e saúde. In: COLÓQUIO INTERNACIONAL SOBRE PODER LOCAL, 10., 2006, Salvador. Anais... Salvador: CIAGS/UFBA, 2006a. 1 CD-ROM.

Governança metropolitana: sobre instituições e organizações. In: COLÓQUIO INTERNACIONAL SOBRE PODER LOCAL, 10., 2006, Salvador. Anais... Salvador: CIAGS/UFBA, 2006b. 1 CD-ROM.

TAPIA, Jorge Bitoun. Concertação, diálogo social e diálogo civil. Brasília: CDES, 2005. Disponível em: <http://www.cdes.gov.br> .

TEIXEIRA, Marco Antonio C. Construindo o pacto para a ação: o caso da Região Metropolitana da Baixada Santista. In: COLÓQUIO INTERNACIONAL SOBRE PODER LOCAL, 10., 2006, Salvador. Anais... Salvador: CIAGS/UFBA, 2006. 1 CDROM.

TONELLA, Celene. Poder local e políticas públicas: o papel dos conselhos gestores. Maringá: Editora da UEM, 2006.

VAINER, Carlos B. Lugar, região, nação, mundo: explorações históricas do debate acerca das escalas de ação política. Revista Brasileira de Estudos Urbanos e Regionais, v.8, n.2, p.9-29, nov. 2006. 